\title{
ANÁLISE DO COMPORTAMENTO DO CONSUMIDOR ESPORTIVO EM RELAÇÃO À ASSOCIAÇÃO, CONSCIÊNCIA E FIDELIDADE DE MARCA: UM ESTUDO DE CASO DA MARATONA DE SÃO PAUULO
}

\author{
${ }^{1}$ Eduardo de Oliveira C. Carlassara \\ ${ }^{2}$ Pedro Lucas Leite Parolini \\ ${ }^{3}$ Ary José Rocco Junior
}

\section{RESUMO}

Nos últimos anos, o mercado de corrida de rua apresentou forte crescimento e evolução. Nesse cenário, empresas passam a adotar os eventos de corridas de rua como plataforma de relacionamento com o público praticante em questão. O objetivo do presente artigo é analisar o comportamento do consumidor esportivo em relação à associação, consciência e fidelidade a determinada marca de material esportivo, em detrimento de outra. Para cumprir o objetivo do trabalho, foi utilizado como metodologia o estudo de caso, por meio da aplicação de questionário misto, no evento Maratona de São Paulo. Após a análise dos dados coletados, notou-se uma forte presença da antiga patrocinadora sendo citada como a atual patrocinadora da Maratona. Além disso, em relação à associação do público com relação à marca da qual gostaria que patrocinasse o evento, a antiga patrocinadora foi a mais citada. Os resultados sugerem que uma correta estruturação e planejamento do patrocínio esportivo, contemplando as quatro etapas do MDPE (objetivo, seleção, ativação e mensuração), aumentam a chance de se obter sucesso sobre o investimento realizado.

Palavras-chave: patrocínio esportivo, branding, corridas de rua

\section{ANALYSIS OF SPORT CONSUMER BEHAVIOR REGARDING THE ASSOCIATION , AWARENESS AND BRAND LOYALTY : A CASE STUDY OF SÃO PAULO MARATHON}

\begin{abstract}
In recent years, street running market showed strong growth and evolution. In this scenario, companies start to adopt street racing events as relationship platform with the consumer of this sport. The aim of this paper is to analyze the sport consumer behavior regarding the association, conscience and loyalty for certain sporting goods brand over another. To achieve the objective of the article, was used as the case study methodology through the application of mixed questionnaire, at the event Marathon of São Paulo. After analyzing the data collected, there has been a strong presence of the old sponsor being cited as the current sponsor of the Marathon. Moreover, in relation to public consciousness regarding the brand that would like to sponsor the event, the old sponsor was the most remembered. The results suggest that a correct structuring and planning of sports sponsorship, covering the four stages of GSAM (goal, selection, activation and measurement), increase the chance to succeed on investment.
\end{abstract}

Keywords: sports sponsorship, branding, street running

\footnotetext{
${ }^{1}$ Mestrando em Gestão e Marketing Esportivo pela Universidade de São Paulo - EEFE/USP, São Paulo, (Brasil). Experiência nas áreas de Comunicação, Marketing e Gestão do Esporte. E-mail eduardo.carlassara@usp.br

${ }^{2}$ Mestrando em Gestão e Marketing Esportivo pela Universidade de São Paulo - USP, São Paulo, (Brasil) Professor Convidado a Ministrar Aula do Tema: Marketing Esportivo e Produção de Eventos de Corrida de Rua. E-mail: pedro-parolini@usp.br

${ }^{3}$ Pós-Doutor em Ciências da Comunicação pela Universidade de São Paulo - ECA/USP, São Paulo, (Brasil). Professor em Regime de Turno Completo da Universidade de São Paulo - EEFE/USP, Brasil

E-mail: aryrocco@usp.br
} 


\section{INTRODUÇÃO}

O mercado de corrida de rua cresceu e se transformou nos últimos anos. As provas da modalidade passaram de eventos que visavam a performance dos participantes, com a adesão principalmente de atletas, para eventos com o público amador que participa com o intuito de praticar atividade física e se entreter ao mesmo tempo.

Para que essas provas atendam às novas expectativas dos corredores, que muitas vezes pagam altos valores pela sua inscrição, é necessário que haja qualidade de serviço oferecida em todas as etapas do evento, da inscrição à divulgação do resultado final. Isso tem um custo financeiro e monetário que, frequentemente, é financiado pelos patrocinadores do evento.

O crescimento da corrida de rua nos últimos anos pode ser comprovado através de levantamento feito pela Federação Paulista de Atletismo (FPA) (2015), em que o número de participantes de eventos de corrida de rua cresceu $450 \%$ de 2004 a 2014. Outro dado que comprova esse crescimento do mercado running foi a pesquisa feita pela Deloitte (2011), empresa de consultoria empresarial, que apontou a corrida de rua como o segundo esporte mais praticado pelos os brasileiros, ficando atrás apenas do futebol.

Percebendo essa nova configuração de eventos da modalidade (evento espetáculo) e o crescimento do número de participantes, empresas de diversos segmentos vislumbram na corrida de rua um espaço para ativar suas marcas e se relacionar com esse público, também consumidor.

Nesse mercado, algumas provas se destacam pela tradição, estrutura oferecida aos atletas, organização, número de participantes e aporte de patrocinadores, como, por exemplo, a Maratona de São Paulo. Por tais motivos, a prova foi escolhida como objeto deste estudo.

$\mathrm{O}$ presente artigo pretende analisar $\mathrm{o}$ comportamento do consumidor esportivo em relação à associação, consciência e fidelidade a determinada marca de material esportivo, em detrimento de outra, sua concorrente, na Maratona de São Paulo.

No processo de coleta de dados, os autores perceberam que um contingente razoável de participantes do evento, quando questionado sobre a associação entre marca esportiva e o evento Maratona de São Paulo, se lembrava da Adidas, marca que não patrocina a corrida em questão, mas investe estrategicamente, no "dia a dia", no relacionamento com o participante corredor.

Por outro lado, a empresa patrocinadora oficial da Maratona de São Paulo, no segmento material esportivo, foi a Fila. A diferença de estratégias adotadas pelas duas empresas, a Adidas investindo no relacionamento cotidiano com os atletas e a Fila patrocinando diretamente o evento, motivou a realização deste nosso estudo.

Assim, o objetivo deste artigo é investigar, entre as duas marcas esportivas - Adidas e Fila -, a relação entre associação, consciência e fidelidade de marca no evento Maratona de São Paulo 2015. Como resultado final, e em função das informações obtidas, pretendemos avaliar a efetividade das estratégias de relacionamento diferenciadas, adotadas pelas duas empresas. Resulta aqui, nessa última análise, nossa principal contribuição para a área de gestão do esporte.

Para o cumprimento de tais objetivos, um questionário foi aplicado aos consumidores de corrida de rua devidamente inscritos na prova da edição de 2015.

\section{Marketing e Patrocínio Esportivo}

De acordo com Mullin et al. (2004), o marketing esportivo se volta para as necessidades e desejos dos consumidores esportivos através de processos de troca. Dentro desse cenário, uma das ferramentas do marketing esportivo utilizadas por empresas que não são organizações esportivas e que percebem no esporte um meio para se posicionar é o patrocínio esportivo.

Ainda segundo Mullin et al. (2004), o patrocínio esportivo está baseado em um conjunto de atividades vinculadas ao processo de comunicação que faz uso do marketing do esporte e do estilo de vida a ele associado, para transmitir mensagens a determinado público-alvo. O patrocínio viabiliza que empresas se estabeleçam na memória de seus consumidores e se favoreçam dos aspectos de positividade atribuídos aos valores do esporte, através de ligações formadas com eventos, clubes, entidades ou projetos esportivos (Machado, 2004).

Dessa forma, o patrocínio esportivo pode ser compreendido como um instrumento da comunicação em marketing, através do qual a transmissão do nome, imagem e/ou produto da empresa realiza-se por meio do esporte (Fernandes, 2009).

Quando classificados de acordo com seus tipos, os patrocínios se distinguem em patrocínio de notoriedade, patrocínio de credibilidade ou patrocínio de imagem (Brochand et al., 1999). O primeiro atende ao objetivo de elevação do conhecimento da empresa ou dos seus produtos; o segundo objetiva promover o reconhecimento e experiência da empresa na sua área de atuação; enquanto a terceira classificação atende ao objetivo de reforçar a imagem da empresa ou seus produtos, com a formação de vínculo entre marca e esporte. 
O patrocínio esportivo deve ser capaz de auxiliar a empresa a atingir objetivos específicos, dentre os quais: aumento de vendas, conquista de mercado, conhecimento da marca/empresa, influência da percepção e atitude de consumidores, realização de ações de hospitalidade corporativa, alcance de formadores de opinião por meio de exposição na mídia, criação de uma relação de proximidade com comunidades próximas e até mesmo satisfação do interesse pessoal de um executivo (Meenaghan, 2001).

Para atingir tais objetivos, as empresas utilizam estratégias de patrocínio que podem variar de acordo com o que se busca. A ativação de patrocínio, por exemplo, está baseada na estratégia de aumentar a ligação entre patrocinador, patrocinado, consumidor e vendas, por meio de ações ligadas ao patrocínio, que oferecem experiências aos envolvidos, criando uma forte relação com a marca patrocinadora (Parolini \& Rocco Junior, 2015).

Sá e Almeida (2012) apresentam um Modelo de Decisão de Patrocínio Esportivo (MDPE) (Figura 1) sustentado por quatro pilares fundamentais: objetivo (motivação), seleção, ativação e mensuração. Tais pilares fazem parte do processo de tomada de decisão em relação ao patrocínio esportivo. Todos são executados em sequência, porém, interligados de uma forma sistêmica (Parolini \& Rocco Junior, 2015).

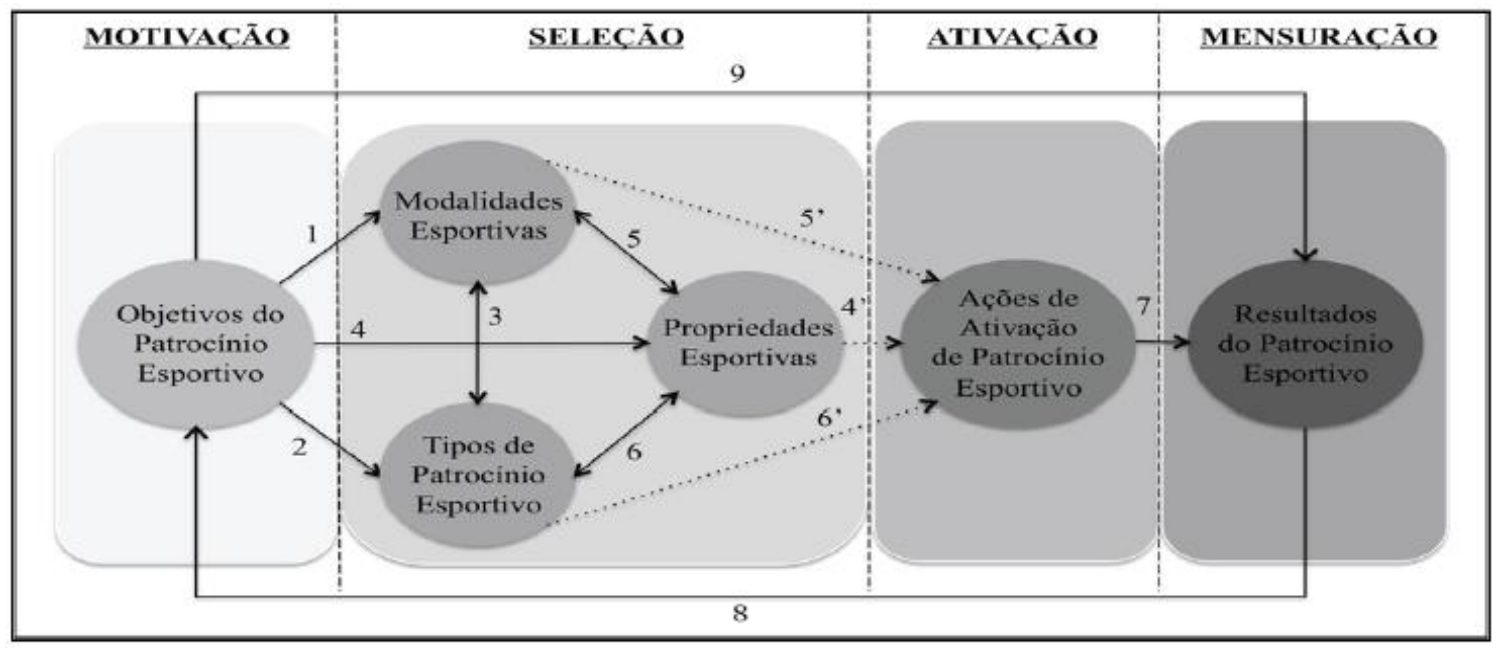

Figura 1 - Modelo de Decisão de Patrocínio Esportivo (MDPE) - (Parolini \& Rocco Junior, adaptado de Sá \& Almeida, 2012).

De acordo com o primeiro pilar do MDPE, o objetivo (motivação) de patrocinar o esporte pode apresentar grandes diferenças, em especial quando falamos em sua aplicabilidade (Geng, Burton \& Blakemore, 2002).

O segundo pilar, mostrado por Sá e Almeida (2012), aponta a maneira como deverá ser a seleção do patrocínio, de acordo com dois pontos cruciais para a tomada de decisão: o que patrocinar (eventos, times, atletas etc.) e qual modalidade patrocinar (vôlei, atletismo, basquete etc.). Tais pontos devem estar de acordo com os objetivos da empresa em questão, bem como serem coerentes com público-alvo que a empresa deseja atingir (Parolini \& Rocco Junior, 2015).

O terceiro pilar é a ativação de patrocínio que consiste na estratégia de aumentar a ligação entre patrocinador, patrocinado, consumidor e vendas, por meio de ações ligadas ao patrocínio, que oferecem experiências aos envolvidos, criando uma forte relação com a marca patrocinadora (Parolini \& Rocco Junior, 2015).
Por fim, o quarto pilar considerado no processo do patrocínio esportivo é a sua mensuração. Nesse ponto, apesar do aumento crescente da prática de patrocínio esportivo, já citado anteriormente, existem situações em que os resultados não são satisfatórios. De acordo com Roy e Cornwell (2004), em alguns casos tais patrocínios não são avaliados e mensurados adequadamente pelos patrocinadores.

\section{Branding e Consciência de Marca}

De acordo com a American Marketing Association (AMA) (2016), a marca pode ser definida como: "Um nome, termo, sinal, símbolo, desenho - ou combinação desses elementos - que deve identificar os bens ou serviços de uma empresa ou grupo de empresas e diferenciá-los dos da concorrência" (American Marketing Association, 2016).

Nesse sentido, as marcas são as responsáveis pela caracterização da identidade da empresa, 
identidade esta que irá proporcionar a diferenciação da mesma perante seus concorrentes.

Uma das características mais importantes para que a marca crie sua identidade é a presença de uma personalidade marcante. De acordo com Aaker (2014), a personalidade pode ser definida como o conjunto de características humanas associadas às marcas, afetando percepções e comportamentos, destacando-se, assim, na multidão.

Todas essas características associadas às marcas dão a elas uma posição de destaque nas empresas. Sendo assim, Aaker (2014) sugere que as marcas devem ser tratadas como ativos das empresas, passando do tático e reativo ao estratégico e visionário.

Uma vez parte do ativo da empresa, as marcas passam a fazer parte do plano estratégico das mesmas e a buscar uma vantagem competitiva perante seus receptores, surge, assim, o conceito de brand equity proposto por Aaker (2007a) (apud. Moreira et al., 2013).

Brand Equity é um conjunto de ativos (e obrigações) inerentes a uma marca registrada e a um símbolo, que é acrescentado ao (ou subtraído do) valor proporcionado por um produto ou um serviço em benefício da empresa ou de seus clientes (Aaker, 2007b, p. 18).

As principais dimensões associadas ao conceito de brand equity são a consciência de marca, as associações de marca e a fidelidade da base de clientes (Aaker, 2014). A consciência de marca está intimamente ligada a um sinal de sucesso e comprometimento da mesma, demonstrando que, se há reconhecimento, isso não é por acaso. Segundo Aaker (2014), a consciência pode afetar a probabilidade de a marca ser lembrada em momentos importantes do processo de compra, ganhando destaque no leque de marcas que o cliente considera.

As associações de marca, por sua vez, são o conjunto de fatores que ligam o cliente à marca, tais como: atributos, qualidade, design, inovação, dentre outros. Tais associações podem ser a base da relação com os clientes e a consequente fidelização dos mesmos. Saber desenvolver associações e criar programas para fortalecê-las são pontos cruciais para a gestão das marcas como ativo (Aaker, 2014).

Por fim, a fidelidade de marca é peça-chave para a criação e durabilidade do valor associado a ela, bem como a lealdade de seus consumidores. Segundo Aaker (2014), um dos objetivos da construção da marca é ampliar o tamanho e intensidade de cada segmento de fidelidade, tornando a base do relacionamento com o cliente mais consistente no longo prazo e mais rica, profunda e significativa.
Assim sendo, tais dimensões do brand equity são de extrema importância na elaboração da discussão dos resultados obtidos no presente estudo e serão novamente abordadas mais à frente.

\section{Mercado de Corrida de Rua e a Maratona de São Paulo}

A Corrida de Rua é definida segundo a Federação Internacional das Associações de Atletismo - IAAF (2015) como prova de pedestrianismo e é praticada com distâncias oficiais entre 5 a 100 quilômetros $(\mathrm{km})$. No mercado atual, as distâncias de 5 $\mathrm{km}$ e $10 \mathrm{~km}$ são mais comuns em eventos, pois conseguem atrair tanto praticantes antigos da modalidade quanto aqueles que estão iniciando a prática do pedestrianismo.

Nos últimos anos, com a necessidade de novos desafios pelos corredores, provas de aventura, corrida de obstáculos, revezamento de equipes, meias maratonas $(21 \mathrm{~km})$ e maratonas $(42 \mathrm{~km})$ começaram a ganhar cada vez mais o apreço daqueles que desejam praticar a modalidade. Essas provas vêm se tornando um importante nicho de mercado a ser explorado pelas produtoras de eventos esportivos (Máquina do Esporte, 2015).

O mercado de corrida de rua no país teve seu crescimento exponencial na década de 1990, período no qual Bottenburg et al. (2010) creditam como o segundo running boom. Segundo os autores, nessa época, os eventos de corrida de rua começaram a se configurar como eventos de entretenimento, com mais atrativos para os participantes que ali se inscreviam. Entre esses atrativos, podemos citar músicas, chips de cronometragem, kits de participação, camisetas personalizadas, trajetos diferenciados, entre outros, os quais, cada vez mais, conquistavam um público que tinha o anseio de praticar a modalidade e se entreter ao mesmo tempo.

Esse mercado, segundo Palhares et al. (2012), é dividido em prática, produção e promoção, cada um composto por seu agente específico, como apresentado no Quadro 1.

O evento corrida de rua ou pedestrianismo está inserido no segmento prática, e todos os outros agentes são envolvidos em torno desses eventos. Por exemplo, as academias fitness incentivam os seus clientes a participar dessas corridas, bem como as assessorias esportivas que elaboram programas de treinos voltados especificamente para esse público corredor. Por outro lado, no segmento promoção, os eventos promocionais vêm ganhando cada vez mais notoriedade. 


\begin{tabular}{|c|c|}
\hline $\begin{array}{l}\text { PRÁTICA OFERECIDA AO } \\
\text { CONSUMIDOR }\end{array}$ & $\begin{array}{l}\text { Iniciativa privada - assessorias esportivas de corrida de rua } \\
\text { Organizações mantidas por sócios - clubes de corrida } \\
\text { Academias de fitness e esportes } \\
\text { Pedestrianismo - atividade oficial em entidades de administração de } \\
\text { atletismo que organizam eventos em geral de cunho competitivo, como } \\
\text { IAAF, AIMS, CBAt, federações, estados, prefeituras. }\end{array}$ \\
\hline PRODUÇÃO & $\begin{array}{l}\text { Equipamentos e Acessórios - monitores, vestuário, calçados,ipods, } \\
\text { hidratação, GPS. } \\
\text { Instrução de fitness - produção técnica } \\
\text { Acompanhamento - médico, nutricional, RPG, avaliação fisica }\end{array}$ \\
\hline $\begin{array}{c}\text { PRODUTOS OFERECIDOS } \\
\text { PARA PROMOVER O ESPORTE }\end{array}$ & $\begin{array}{l}\text { Produtos e eventos promocionais } \\
\text { Mídia -fotos, filmagens, clips, revistas, sites. } \\
\text { Patrocínio de eventos - corridas, revezamentos }\end{array}$ \\
\hline
\end{tabular}

\section{Quadro 1 - Segmentos da Indústria da Corrida de Rua}

Fonte: Palhares et al. (2012)

Como exemplo desses eventos promocionais do mercado de corrida de rua no país, podemos citar os clubes de futebol da Série A do Campeonato Brasileiro que estão, recentemente, investindo em corridas próprias a fim de estreitar o relacionamento com seu torcedor por meio de eventos dessa natureza (Máquina do Esporte, 2015).

Dos vinte clubes da Série A, pelo menos oito promoveram seu evento de corrida de rua no ano de 2015. Foram eles: Corinthians, Atlético Mineiro, Internacional, Cruzeiro, Coritiba, Ponte Preta, Grêmio e Santos.

$\mathrm{Na}$ corrida realizada pelo Sport Club Corinthians Paulista, o número de corredores chegou a 4 mil, e o evento contou com alguns atrativos para os participantes, como um trecho sendo realizado no entorno da arena do clube e no Dia da Consciência Negra, data significativa para a agremiação.

Outros dados que quantificam esse crescimento vêm da FPA (2015), que publicou um relatório com o número de provas realizadas no estado e o número de participantes envolvidos nesses eventos. Segundo a entidade, nos anos de 2004 a 2014, o número de corredores no estado de São Paulo cresceu $450 \%$, chegando a 653 mil. O número de eventos da modalidade também vem crescendo, ano após ano, como citado pela FPA (2015) em seu relatório, que aponta a organização de 361 provas em 2014, crescimento de $250 \%$ em relação a 2004 . Dentre essas provas, uma das mais importantes é a Maratona de São Paulo, realizada tradicionalmente no primeiro semestre do ano.

A Maratona de São Paulo é uma das mais tradicionais corridas de rua do país. Sua primeira edição aconteceu ainda nos anos 1990, mais precisamente em outubro de 1995. Foram 21 anos de história até o presente momento e, na última edição, em 2015, a prova contou com 19 mil atletas, divididos em provas de $42 \mathrm{~km}, 15$ milhas $(24,21 \mathrm{~km}), 5$ milhas $(8$ $\mathrm{km})$ e 2 milhas $(3,2 \mathrm{~km})$.
Durante todos esses anos, o trajeto da prova sofreu várias alterações até chegar ao atual percurso, com largada e chegada ao obelisco do Parque do Ibirapuera.

Sua edição de número 22 ocorreu no dia 24 de abril de 2016. Para toda essa estrutura, o evento, em 2015, contou com alguns parceiros, dentre eles alguns patrocinadores como FILA, Caixa Econômica Federal, Gatorade e Café Três Corações.

No formato atual, a Maratona de São Paulo carrega elementos atribuídos ao que Oliveira (2010) denomina de corridas fashion, ou seja, corridas que prezam pelo seu caráter de entretenimento. O públicoalvo dessas corridas são corredores amadores. Tais eventos apresentam alguns atrativos, citados por Bottenburg et al. (2010), como músicas para largada e chegada, camisetas personalizadas, kit de participação e ativações de patrocinadores, este último geralmente feito na forma de estandes montados no local da prova ou brindes entregues nos kits de participação dos atletas inscritos.

Todos esses elementos reforçam o potencial que o mercado de corrida de rua possui. Nesse sentido, estudos que envolvam esse ambiente são cada vez mais importantes para a discussão do atual cenário do marketing esportivo no país.

\section{METODOLOGIA}

Para o trabalho em questão, foi realizada uma pesquisa qualitativa de caráter exploratório, utilizando como método o estudo de caso. Para Creswell (2014), conduzimos pesquisas qualitativas porque, como é o caso em questão, um problema ou questão precisa ser explorado. Por sua vez, ainda segundo Creswell (2014), essa exploração é necessária devido à necessidade de estudar um grupo ou população. Para Gil (2006), o estudo de caso visa explorar situações da vida real, contudo preserva o caráter unitário da pesquisa. Ainda segundo o autor, esse método permite 
descrever a situação do contexto em que se realiza o trabalho. Nesse contexto, utilizamos o evento Maratona de São Paulo, realizado em 17 de maio de 2015.

Como instrumento de pesquisa, desenvolveuse um questionário misto, com questões abertas, fechadas e dependentes, a partir de entrevistas realizadas com especialistas da área, a saber: um acadêmico especialista em patrocínio esportivo, um produtor de eventos de corrida de rua e um patrocinador de modalidade. A amostra foi composta por 198 corredores, todos devidamente inscritos na prova. A coleta de dados foi realizada 48 horas antes da realização da prova, no momento da retirada dos kits. Foi nesse momento que os participantes tiveram seu primeiro contato de fato com o evento e dispunham de mais tempo e tranquilidade para responder ao questionário.

As questões que compunham o instrumento de pesquisa foram estruturadas em dois blocos. $\mathrm{O}$ primeiro bloco foi dividido em cinco questões abertas que compunham três grupos: (1) associação de marca, (2) consciência de marca, e (3) fidelização. As respostas desse bloco foram classificadas em três categorias: qualidade, apreço pela marca e investimento. Já o segundo bloco contemplava perguntas sociodemográficas, necessárias para a elaboração do perfil dos indivíduos entrevistados.

$\mathrm{Na}$ primeira parte, as questões remetiam à associação dos consumidores sobre as marcas patrocinadoras do evento e as preferências, por parte do público, de quais marcas deveriam patrocinar a Maratona de São Paulo. Na segunda parte, as questões eram relacionadas ao sexo do indivíduo, idade, renda mensal e nível de escolaridade.

Quanto à análise dos dados, optamos pelo uso de distribuição de frequência nas respostas fechadas e a técnica de análise de conteúdo, proposta por Bardin (2011), nas questões abertas. Nessa fase, as respostas dos indivíduos da amostra foram analisadas e classificadas em categorias mencionadas anteriormente (qualidade, apreço pela marca e investimento), categorias estas que remetem diretamente à associação de marca, consciência e fidelização.

\section{MARCAS DO ESTUDO ADIDAS}

As origens da marca datam de 1920, quando Adolph Dassler iniciou um pequeno negócio na cidade alemã de Herzogenaurach. O foco de Dassler era a produção de calçados esportivos e malas militares para a subsistência de sua família. Em 1936, Adolph criou a Adidas. Através da constante busca por reconhecimento de seus produtos, a empresa utilizou um design diferenciado, culminando nas três listras, hoje mundialmente conhecidas (Adidas, 2016).

De acordo com informações contidas no site da empresa, a Adidas emprega, atualmente, aproximadamente 53 mil pessoas em 160 países, produzindo mais de 660 milhões de unidades de produtos todos os anos. As vendas mundiais da marca, em 2014, atingiram a casa dos 14 bilhões de euros ${ }^{4}$ (Adidas, 2016). Na América Latina, nos três primeiros trimestres de 2015, as vendas da empresa aumentaram em $15 \%$ se comparadas ao mesmo período de 2014 . Os valores chegaram a 426 milhões de euros no período de $2015^{5}$ (Adidas, 2016). O aumento das vendas da Adidas, no ano de 2015, se deu pelo crescimento específico de suas categorias de produtos comercializados, dentre os quais podemos destacar a importante presença do running.

De acordo com a marca, o segmento running apresentou um aumento de $9 \%$ em vendas nos países que obtiveram crescimento geral de todos os segmentos. Além disso, a categoria atingiu um crescimento de dois dígitos nas vendas de calçados, representados pelos oito milhões de pares do tênis Boost, vendidos em 2015 (Adidas, 2016).

Por fim, o tênis Boost, produto de maior venda e sucesso da categoria, foi usado por todos os vencedores de 64 grandes maratonas de grande conhecimento mundial, evidenciando o sucesso do segmento no ano de 2015 (Adidas, 2016).

\section{FILA}

A origem da marca data do ano de 1911, quando a empresa foi fundada pelos irmãos Fila, na pequena cidade de Biella, na Itália. O objetivo inicial dos irmãos era a confecção de roupas íntimas para moradores da região. Em 1973, a empresa ingressou na área esportiva. $\mathrm{O}$ caráter inovador das roupas da marca conquistou espaço no mercado têxtil esportivo. A FILA, então, apostou no logo composto pela primeira letra de seu nome para criar a identidade da marca que perdura até os dias de hoje (Fila, 2016).

Além de sua forte influência e presença histórica no cenário do tênis mundial, modalidade patrocinada há décadas pela marca, a FILA também possui importante presença no mercado running do Brasil. Através do desenvolvimento de produtos específicos para a modalidade e do patrocínio de grandes corridas brasileiras, bem como atletas de grande expressão mundial, a marca se firmou no cenário da modalidade no país e no mundo.

Pautados em campanhas estreladas por

\footnotetext{
4 Aproximadamente $\mathrm{R} \$ \quad 60.880 .900 .000,00$ em valores atualizados para $1^{\circ}$ de março de 2016. Atualização feita com base no valor de câmbio. Fonte: http://www.oanda.com/lang/pt/currency/converter/

5 Aproximadamente $\mathrm{R} \$ 1.852 .520 .000,00$ em valores atualizados para 1을 de março de 2016. Atualização feita com base no valor de câmbio. Fonte: http://www.oanda.com/lang/pt/currency/converter/
} 
corredores quenianos, a FILA posiciona sua marca em função do atleta, estreitando seus laços com o público consumidor. Segundo Felipe Rosa, gerente de marketing da marca, em entrevista concedida ao portal Máquina do Esporte, especializado em gestão do esporte, o foco da FILA é a busca por um

\section{RESULTADOS E DISCUSSÃO}

O perfil da amostra utilizada no estudo consiste em corredores amadores, dos quais $78 \%$ eram do sexo masculino. Esse público dedica de 3 a 10 horas da semana para seus treinos e pratica a modalidade há, no mínimo, 5 anos. O perfil socioeconômico dos praticantes abordados corresponde a uma renda mensal que ocupa o patamar de 4 a 17 salários mínimos6 e nível de escolaridade representado por ensino superior e/ou pós-graduação. posicionamento diferenciado, pautado na felicidade e bem-estar dos seus consumidores da categoria running (Máquina do Esporte, 2014). Ainda de acordo com o portal Máquina do Esporte (2014), o setor de corridas representou $52 \%$ do faturamento da marca em 2013.

No que diz respeito à pergunta relativa à consciência de marca dos patrocinadores da Maratona de São Paulo, 74\% dos respondentes afirmam lembrar algum patrocinador do evento, enquanto somente $24 \%$ relataram não se recordar de nenhuma marca associada ao evento, e $2 \%$ da amostra não respondeu à pergunta. Essas respostas podem ser visualizadas no gráfico 1 .

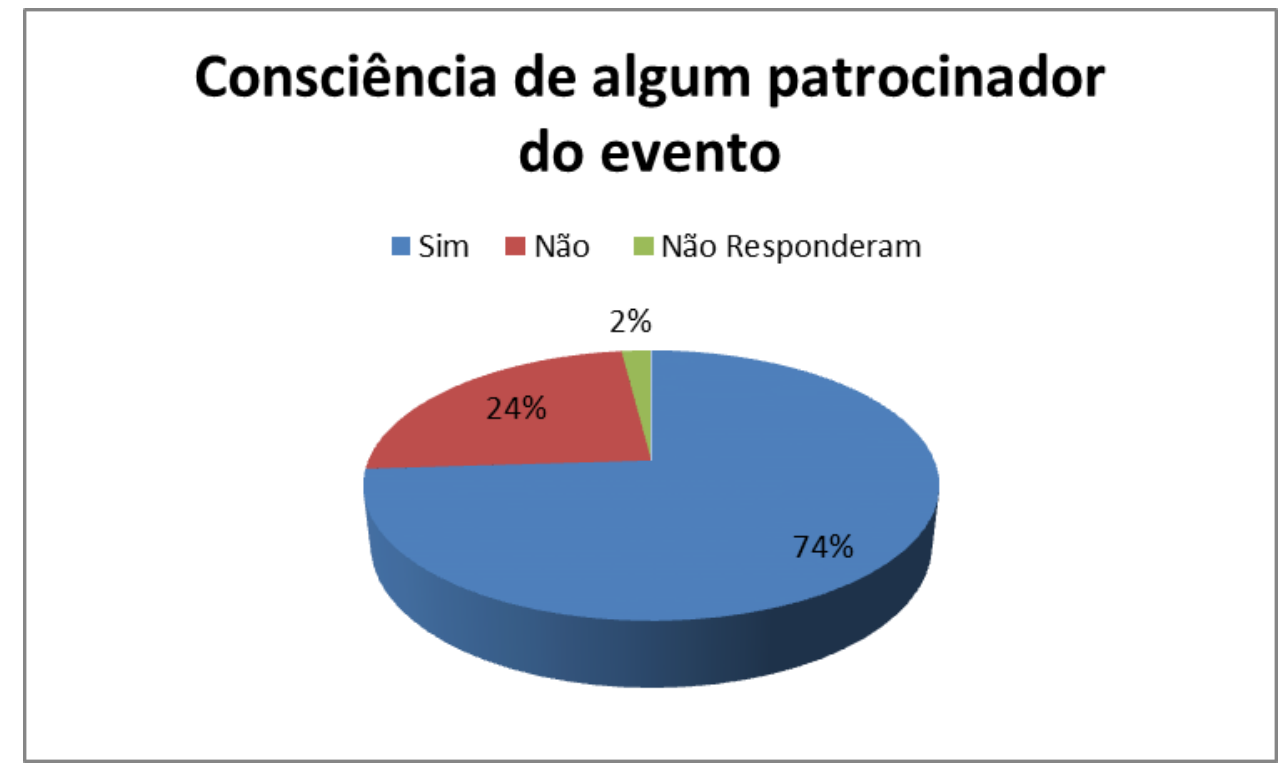

Gráfico 1 - Consciência dos patrocinadores do evento Fonte: Próprios autores

\footnotetext{
6 Aproximadamente de $\mathrm{R} \$ 3.520,00$ a $\mathrm{R} \$ 14.960,00$ em valores atualizados para $1^{\circ}$ de março de 2016. Atualização feita com base no valor do salário mínimo. Fonte: http://drcalc.net/correcao.asp?it=3\&ml=Calc
} 
Com relação às marcas citadas pelos entrevistados, que afirmaram ter consciência de algum patrocinador, estão a Caixa Econômica Federal com $29,06 \%$, seguida pela FILA com $12,20 \%$ dos respondentes, Café Três Corações com 11\%, Globo com $6 \%$ e Adidas e Gatorade com $5,23 \%$. O gráfico 2 ilustra essas empresas citadas como patrocinadoras do evento.

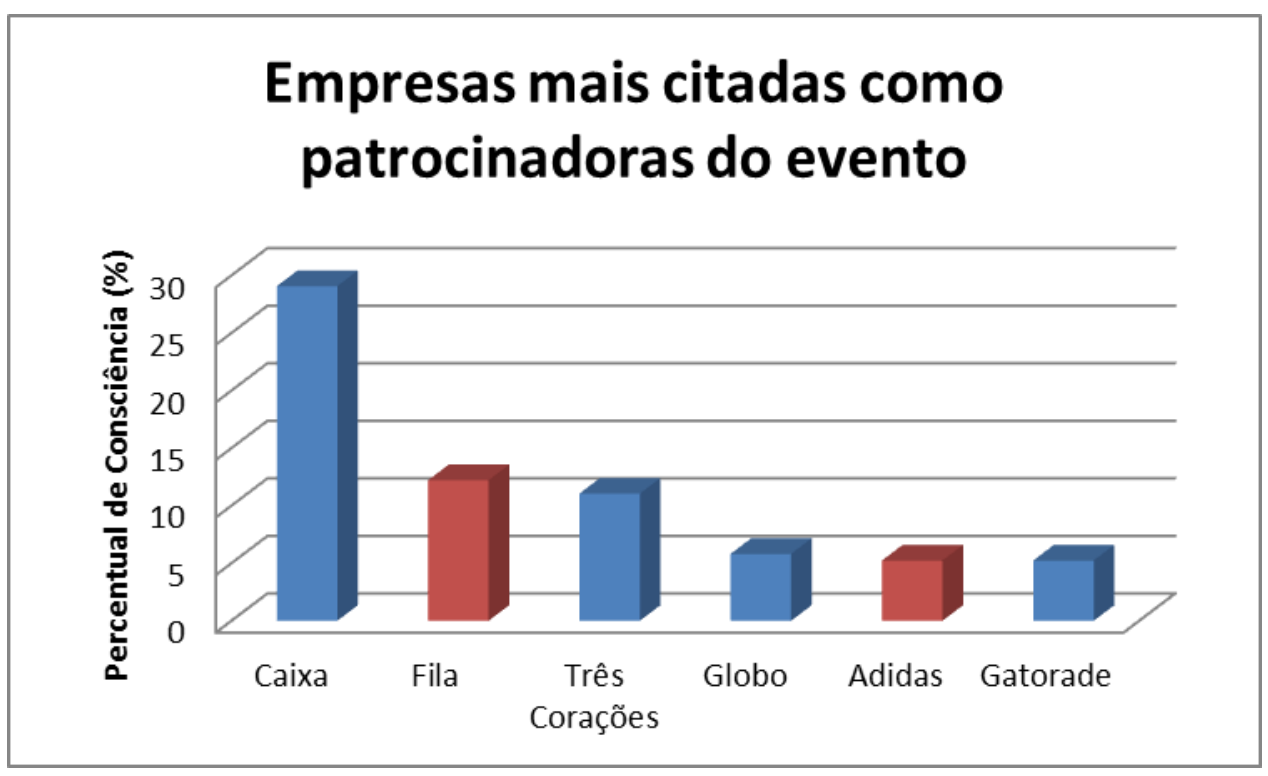

Gráfico 2 - Empresas mais citadas como patrocinadoras do evento Fonte: Próprios autores

Como o objeto central deste estudo são as marcas de artigos esportivos, vale a pena destacar que, dentre as seis marcas mais citadas pelos respondentes como patrocinadoras do evento, chama a atenção o caso da Adidas, que, embora mencionada pelos respondentes participantes do evento, é a única entre as citadas que não faz parte do quadro de patrocinadores da Maratona de São Paulo 2015.

Tal constatação motivou a discussão objeto central deste artigo. A atual empresa de material esportivo patrocinadora da edição de 2015 da prova é a FILA, que foi a apontada como a segunda em número de citações, atrás apenas da Caixa Econômica Federal, também patrocinadora da prova. No entanto, o aparecimento da Adidas entre as mais citadas pelo público respondente é digno de investigação.

Tal porcentagem de citação pode decorrer de alguns fatores. $\mathrm{O}$ primeiro deles pode estar relacionado ao fato de a Adidas ter patrocinado a corrida nas edições de 2010 a 2013, criando o que Aaker (2014) denomina de fidelidade de marca. Tal fidelidade é a peça essencial para que a marca possua durabilidade na mente dos consumidores, os quais se tornam leais a ela.

Outro fator que pode ser apontado, no caso da Adidas, é que tal fidelidade advém de uma forte presença da marca no mercado running, pautado na própria origem da empresa e comprovado pelos investimentos nesse segmento, como calçados e roupas específicos para o público corredor, além da presença como patrocinador em outros eventos da modalidade.

Por fim, os indivíduos elencaram quais empresas eles gostariam que patrocinasse o evento e qual era o motivo para tal escolha. O gráfico 3 apresenta os resultados das quatro empresas mais citadas pelos consumidores. 


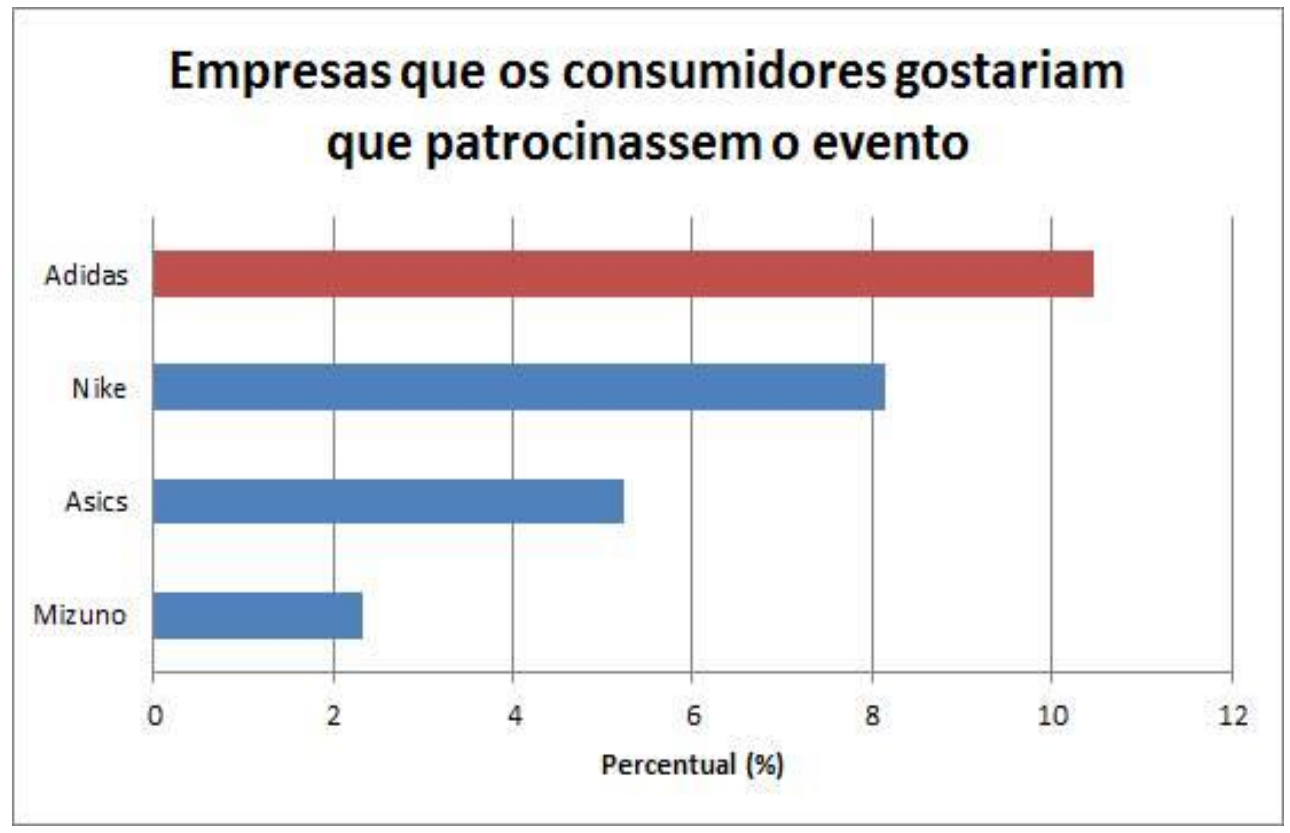

Gráfico 3 - Empresas que os Consumidores Gostariam que Patrocinasse o Evento Fonte: Próprios autores

Por meio da análise do gráfico, podemos notar a presença de quatro empresas especificamente do segmento esportivo. Isso sugere que as pessoas participantes do evento têm consciência de que esses patrocinadores apresentam um maior grau de associação com a atividade que estão patrocinando.

Outro ponto de extrema relevância é o fato de que a Adidas foi novamente associada, agora como marca que os consumidores mais gostariam que patrocinasse o evento, correspondendo a $10,46 \%$ das respostas. Quando indagados sobre o motivo da escolha dessa marca como preferencial para patrocinar o evento, $83 \%$ dos respondentes apontaram a categoria "qualidade do produto" como o principal motivo para tal preferência, enquanto as categorias "apreço pela marca" e "investimento na modalidade" apareceram com $8,5 \%$ cada.

Isso corrobora o que é apontado por Aaker (2014), que a qualidade do produto é um dos fatoreschave para que a marca seja diretamente ligada ao cliente, resultando na fidelização do mesmo. Tal fidelização é importante, pois influi diretamente no processo decisório de compra dos consumidores, pois estes têm tendência a comprar produtos de marcas familiares.

\section{CONCLUSÃO}

Quando o patrocínio esportivo em eventos de corrida é bem estruturado e planejado, contemplando as quatro etapas do MDPE (objetivo, seleção, ativação e mensuração), a chance de se obter sucesso em cima do investimento feito cresce significativamente.
No caso deste estudo, no qual o contexto utilizado foi o da Maratona de São Paulo 2015, a atual marca de material esportivo patrocinadora do evento, a FILA, foi a mais citada. Porém, e o fato é digno de nota, percebemos que a Adidas ainda foi elencada por parte dos corredores como patrocinadora do evento, mesmo a marca tendo deixado de patrocinar a prova em 2013, ou seja, houve uma considerável consciência por parte desses consumidores.

Essa consciência poderia ter ocorrido pelo fato de a empresa ter sido patrocinadora em quatro anos seguidos da Maratona de São Paulo (2010-2013), criando uma relação com seu consumidor ou, então, por estar atuante no mercado ruuning, patrocinando várias outras corridas desse segmento, o que permite um posicionamento da sua marca nesse mercado.

Os resultados encontrados evidenciam um caminho a ser seguido quando falamos de patrocínio esportivo. Planejamento e estratégia bem-sucedida de parceria entre produtor do evento e patrocinador podem gerar benefícios para ambas as partes. No caso específico da Maratona de São Paulo 2015, um patrocinador que investiu durante quatro anos, após dois anos do fim da parceria, ainda é citado como investidor da atual edição. Adicionando a essa consciência, podemos apontar o fato de a mesma empresa ter sido mais mencionada quando foi perguntado aos entrevistados sobre qual delas os consumidores gostariam que patrocinassem esse evento e qual era o motivo dessa escolha. Como observado, o motivo mais referido foi a qualidade do produto, muitas das vezes associado à camiseta entregue junto com o kit da corrida. 
Um bom planejamento estratégico de patrocínio esportivo, aliado à qualidade do produto oferecido, pode ser a combinação perfeita para uma parceria entre patrocinador e patrocinado. Parceria na qual o patrocinador expõe sua marca, produto ou serviço por meio de ativações de patrocínio no evento e, em contrapartida, o patrocinado tem o valor agregado do evento aumentado, o que pode atrair novos consumidores para aquele evento e novos consumidores para a empresa patrocinadora.

É interessante ressaltar que este estudo foi feito em uma prova específica de uma modalidade apenas e, por ser tratar de um estudo de caso, não pode ser generalizado. Porém, os resultados apontam uma direção no patrocínio esportivo que pode ser estudada em outras pesquisas, com outros eventos e provas, em diferentes modalidades e com novos patrocinadores.

Por se tratar de um estudo de caso, os resultados não podem ser generalizados. Para pesquisas futuras, sugere-se a aplicação do mesmo instrumento em outras corridas com os mesmos patrocinadores, para possíveis comparações de resultados. Além disso, aconselha-se o desenvolvimento da mesma pesquisa, utilizando outros esportes e metodologias diferentes, como, por exemplo, estudos quantitativos. Nessa linha, uma excelente opção para a realização de estudos futuros com os mesmos dados obtidos para este artigo é a realização de uma pesquisa quantitativa utilizando modelagem de equações estruturais, em cima de constructos já validados no contexto brasileiro. Por fim, é importante ressaltar a importância do estudo para a área de marketing esportivo, bem como a aplicação deste para o desenvolvimento de planos estratégicos de patrocínio, por parte de empresas que desejam se aliar ao esporte como plataforma de posicionamento no mercado de corrida de rua.

\section{REFERÊNCIAS}

Aaker, D. (2007a). Construindo marcas fortes. Porto Alegre: Bookman.

Aaker, D. (2007b). Como construir marcas líderes. Porto Alegre: Bookman.

Aaker, D. (2014). On Branding. Porto Alegre: Bookman.

Adidas. (2016). Acesso em 25 de janeiro de 2016, de http://www.adidas-group.com/en/group/profile/

Atletismo, F. P. de. (2015). Estatísticas Corrida de Rua 2014. Acesso em 14 de junho de 2015, de $<$ http://www.atletismofpa.org.br/Corrida-de-

Rua/Estat\%C3\%ADstica-2014>
Association, A. M. (2016). About AMA. Acesso em 23 de janeiro de 2016, de $<$ https://www.ama.org/AboutAMA/Pages/Definitionof-Marketing.aspx >

Bardin, L. (2011). Análise de Conteúdo (70th ed.). São Paulo: Almedina Brasil.

Bottenburg, M. V., Hover, P., Scheerder, J. (2010). Don't miss the next boat. Chances and challenges of the second wave of running. New Studies in Athletics, 25(3/4), 125-143.

Brochand, B., Lendrevie, J., Rodrigues, J. \& Dionísio, P. (1999). Publicitor. Lisboa: Publicações Dom Quixote. 559-584.

Creswell, J. W. (2014). Investigação Qualitativa \& Projeto de Pesquisa. São Paulo: Penso.

Deloitte. (2011). Muito além do Futebol: Estudos sobre esportes no Brasil. Acesso em 10 de junho de 2015 , de http://www.deloitte.com.br/Comunicados/ReleasePesq uisaEsportes.pdf >

Esporte, M. do. (2014). Quenianos inspiram posicionamento da Fila na corrida de rua. Acesso em 25 de janeiro de 2016, de $<$ http://maquinadoesporte.uol.com.br/artigo/quenianosinspiram-posicionamento-da-fila-na-corrida-derua_26920.html\#ixzz3yGxtxoqr>

Esporte, M. do. (2015). Análise: Corrida de rua pode valorizar as marcas dos clubes. Acessado em 10 de Dezembro de 2015. <http://maquinadoesporte.uol.com.br/artigo/analisecorrida-de-rua-pode-valorizar-marcas-dosclubes_29107.html>

Fernandes, A. (2009). Activação de Patrocínios Desportivos. Universidade de Lisboa 1-90.

FILA. (2016). Acesso em 25 de janeiro de 2016, de http://www.fila.com.br/

Geng, L., Burton, R. \& Blakemore, C. (2002). Sport sponsorship in China: transition and evolution. Sport Marketing Quarterly. 11(1). 20-32.

Gil, A. C. (2006). Métodos e técnicas de pesquisa social (5th ed.). São Paulo: Atlas.

International Association of Athletics Federations - IAAF (2015). History. Acesso em 10 de outubro de 2015, de <http://www.iaaf.org/about-iaaf/history> 
Machado, J. (2004). Marketing Esportivo: Um estudo sobre o crescimento das instituições de ensino na prática do patrocínio esportivo. SEMEAD. 1-11.

Meenaghan, T. (2001). Understanding Sponsorship Effects. Psychology \& Marketing. 18, 95122.

Moreira, R. (2013). Personalidade das Marcas Esportivas. Intercom - Sociedade Brasileira de Estudos Interdisciplinares da Comunicação. Rio de Janeiro: XXXVI Congresso Brasileiro de Ciências da Comunicação.

Mullin, B., Hardy, S. \& Sutton, W. (2004). Marketing Esportivo. Porto Alegre: Artmed/Bookman.

Oliveira, S. N. (2010). Lazer sério $e$ envelhecimento: loucos por corrida. Universidade Federal do Rio Grande do Sul.

Palhares, J. M., Bastos, F. da C., Mazzei, L. C., \& Benetti, M. (2012). Perfil e preferências de praticantes de corrida de rua: um estudo preliminar. Revista Mineira de Educação Física, 1, 1664-1673.

Parolini, P. \& Rocco Junior, A. (2015). Patrocínio Esportivo no Brasil: uma análise qualitativa da produção acadêmica brasileira sobre o tema. Intercom - Sociedade Brasileira de Estudos Interdisciplinares da Comunicação. Rio de Janeiro: XXXVIII Congresso Brasileiro de Ciências da Comunicação.

Roy, D. \& Cornwell, T. (2004). The Effects of Consumer Knowledge on Responses to Event Sponsorships. Psychology \& Marketing. 21, 185.

Sá, B. \& Almeida, V. (2012). Motivação, Seleção, Ativação e Mensuração do Patrocínio Esportivo. V Encontro de Marketing ANPAD. Curitiba. 